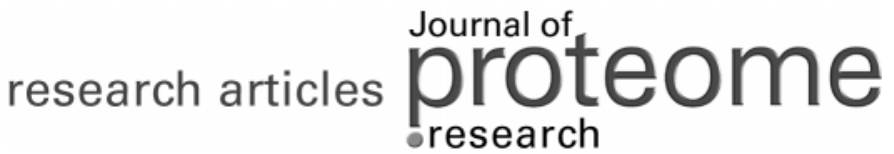

\section{A Proteomic Approach toward the Selection of Proteins with Enhanced Intrinsic Conformational Stability}

\author{
Vesna Prosinecki, ${ }^{\dagger}$ Hugo M. Botelho, ${ }^{\dagger}$ Simona Francese, ${ }^{\ddagger}$ Guido Mastrobuoni, ${ }^{\ddagger}$ \\ Gloriano Moneti, ${ }^{\ddagger}$ Tim Urich, ${ }^{\S}$ Arnulf Kletzin, ${ }^{\S}$ and Cláudio M. Gomes ${ }^{*, \dagger}$
}

\begin{abstract}
Instituto Tecnologia Química e Biológica, Universidade Nova de Lisboa, Oeiras, Portugal, Mass Spectrometry Centre, University of Florence, Florence, Italy, and Institute of Microbiology and Genetics, Darmstadt, Germany
\end{abstract}

Received May 25, 2006

\begin{abstract}
A detailed understanding of the molecular basis of protein folding and stability determinants partly relies on the study of proteins with enhanced conformational stability properties, such as those from thermophilic organisms. In this study, we set up a methodology aiming at identifying the subset of cytosolic hyperstable proteins using Sulfurispharea sp., a hyperthermophilic archaeon, able to grow between 70 and $97{ }^{\circ} \mathrm{C}$, as a model organism. We have thermally and chemically perturbed the cytosolic proteome as a function of time (up to $96 \mathrm{~h}$ incubation at $90^{\circ} \mathrm{C}$ ), and proceeded with analysis of the remaining proteins by combining one- and two-dimensional gel electrophoresis, liquid chromatography fractionation, and protein identification by $\mathrm{N}$-terminal sequencing and mass spectrometry methods. In total, 14 proteins with enhanced stabilities which are involved in key cellular processes such as detoxification, nucleic acid processing, and energy metabolism were identified including a superoxide dismutase, a peroxiredoxin, and a ferredoxin. We demonstrate that these proteins are biologically active after extensive thermal treatment of the proteome. The relevance of these and other targets is discussed in terms of the organism's ecology. This work thus illustrates an experimental approach aimed at mining a proteome for hyperstable proteins, a valuable tool for target selection in protein stability and structural studies.
\end{abstract}

Keywords: Archaea $•$ Thermophiles $•$ Protein Folding and Stability • Superoxide dismutase $\bullet$ Ferredoxin

\section{Introduction}

Thermophilic organisms are a valuable source of proteins with very high stability, the so-called hyperstable proteins. At working temperatures above $80^{\circ} \mathrm{C}$, the stability of the proteome is kept due to the combined effect of several factors. ${ }^{1,2}$ Among these, extrinsic factors like the compatible solutes, acting as chemical stabilizers, such as trehalose and $\beta$-mannosylglycerate are particularly relevant. ${ }^{3}$ The concentration of these molecules in the cell can be very high, thus, resulting in a stabilizing effect which adds to intracellular protein crowding effects. However, intrinsic factors play a key role in accounting for the high thermal stability of thermophilic proteins. Protein stability relies essentially on the additive effect of noncovalent bonds of weak magnitude, ${ }^{4}$ which result in an overall stabilization of the folded native conformation. Although there is not a general rule that accounts for the molecular determinants, a series of particularities have been outlined in proteins from thermophiles which could explain their increased stability. ${ }^{1,2}$ Surface ion pairs, a

* To whom correspondence should be addressed. Cláudio M. Gomes, Instituto Tecnologia Química e Biológica. Universidade Nova de Lisboa, Av. República 127, 2780-756 Oeiras, Portugal. Tel: +351 214469332. Fax: +351 214411277. E-mail, gomes@itqb.unl.pt; URL, http://www.itqb.unl.pt/pbfs.

$\dagger$ Universidade Nova de Lisboa.

‡ University of Florence.

${ }^{\S}$ Institute of Microbiology and Genetics. solvent-exposed hydrophobic surface, and efficient anchoring of terminal extensions and loop regions seem to be particularly relevant in enhancing protein stability. Thermophilic proteins have an emerging interest both from a fundamental and an applicative point of view. In particular, thermophilic enzymes are of interest due to their potential application in biotechnological or industrial processes where a biological catalyst is used. ${ }^{5,6}$ Moreover thermophilic proteins constitute also excellent working models in more fundamental studies aiming at the elucidation of the molecular determinants of a particular fold $^{7-9}$ or protein structure; for example, see refs 6,10 . This knowledge is essential for the understanding of folding mechanisms and contributes to the design of better structure prediction algorithms.

Following our long standing interest in the study of the stability properties of thermophilic proteins (e.g., see refs 8 , $11-18)$, we set up a methodology which aims at identifying a subset of the proteome of thermophilic organisms containing the most intrinsically stable proteins. The rationale for our approach is based on previous reports of thermophilic proteins, which at physiological $\mathrm{pH}$ conditions $(\mathrm{pH} \mathrm{6-7)} \mathrm{remain} \mathrm{folded}$ and functional even upon extensive incubation periods at high temperatures; for example, see ref 11. The thermoacidophilic archaea Sulfurisphaera ${ }^{19}$ was selected as a model: it is a facultative anaerobe, living in acidic, hot, solfataric springs at 
high temperatures with an optimal growth temperature of 85 ${ }^{\circ} \mathrm{C}$, tolerating a broad $\mathrm{pH}$ range from 1 to 5.5 , with an optimal $\mathrm{pH}$ at 2. Its genome, which is currently being sequenced, is more than $90 \%$ identical to those of the closely related organism Sulfolobus tokodaii, ${ }^{20}$ for which there is inclusively proteomic data available. ${ }^{21}$ Its broad growth temperature range (70-97 ${ }^{\circ} \mathrm{C}$ ) allowed the study and analysis of the proteome obtained from cells grown close to physiological growth temperature extremes. We have outlined a protocol in which the cytosolic proteome of Sulfurisphaera was chemically and thermally perturbed as a function of time. The impact of the destabilization was assessed by combining several approaches including liquid chromatography, SDS-PAGE, two-dimensional gel electrophoresis (2DE), N-terminal sequencing, and mass spectrometry methods for the identification of purified proteins and spots of interest. A set of proteins with enhanced stabilities was identified, and their relevance on a thermophilic background is discussed.

\section{Experimental Procedure}

Cell Mass and Preparation of the Cytosolic Extract. Sulfurisphaera sp. cells were grown at $72^{\circ} \mathrm{C}$ (SulfCP72) and $92{ }^{\circ} \mathrm{C}$ (SulfCP92) according to published procedures. ${ }^{22}$ Preparation of the cellular fractions was essentially performed as described ${ }^{23}$ using $40 \mathrm{mM}$ phosphate buffer, $\mathrm{pH}$ 6.5, throughout all stages. All steps were carried out at $4{ }^{\circ} \mathrm{C}$ in the presence of the protease inhibitor PMSF (0.5 mM). The soluble extracts were divided in small portions and stored at $-20{ }^{\circ} \mathrm{C}$ prior to use.

Thermal and Chemical Perturbation Protocols. The soluble extracts from SulfCP72and SulfCP92 were perturbed by two different protocols in $40 \mathrm{mM}$ phosphate buffer, $\mathrm{pH}$ 6.5. The thermal perturbation included incubation at $90{ }^{\circ} \mathrm{C}$ for up to $96 \mathrm{~h}$ and sampling every $24 \mathrm{~h}$. In the second perturbation protocol, $1 \mathrm{M}$ of the chemical denaturant guanidinium hydrochloride $(\mathrm{GuHCl})$ was added to the samples, with subsequent incubation periods at $90^{\circ} \mathrm{C}$. In both cases, after sampling, less stable precipitated proteins were removed by $10 \mathrm{~min}$ centrifugation at $14000 \mathrm{rpm}$ on a bench centrifuge at $4{ }^{\circ} \mathrm{C}$.

Liquid Chromatography Analysis of Perturbed Proteomes. Soluble proteomes obtained by both perturbation protocols were chromatographically resolved using anionic exchange. A HiTrap Q-sepharose FF ( $5 \mathrm{~mL}$ ) column equilibrated with 40 $\mathrm{mM}$ phosphate buffer, $\mathrm{pH}$ 6.5, was used, and fractions eluted with a linear gradient up to $1 \mathrm{M} \mathrm{NaCl}$. Separated peaks were concentrated (Amicon, $5 \mathrm{kDa}$ ) and loaded into a gel filtration column (Superdex-75). Protein profiles were obtained monitoring absorption at $280 \mathrm{~nm}$. Eluted fractions were checked by $12.5 \%$ SDS-PAGE and UV-visible spectrum.

2D Electrophoresis. For 2D-PAGE, samples were separated in the first dimension by isoelectrofocusing (IEF). Samples of thermally treated as well as not treated soluble extract were precipitated overnight with $10 \%$ tricloroacetic acid (TCA) in acetone, and the pellet was additionally washed with acetone and left to air-dry before solubilizing in immobilized $\mathrm{pH}$ gradient IPG rehydration buffer composed of $8 \mathrm{M}$ urea, 2\%(w/ v) CHAPS, $60 \mathrm{mM}$ DTT, and $0.5 \%$ IPG buffer (pH 3-11, Amersham Biosciences). Samples were rehydrated using $13 \mathrm{~cm}$ long pH 3-11 NL IPG strips (Amersham Biosciences). Isoelectric focusing was carried out using the following scheme: $30 \mathrm{~V}$ for $12 \mathrm{~h}, 250 \mathrm{~V}$ for $250 \mathrm{~V} / \mathrm{h}, 500 \mathrm{~V}$ for $750 \mathrm{~V} / \mathrm{h}, 1000 \mathrm{~V}$ for 1500 $\mathrm{V} / \mathrm{h}, 2500 \mathrm{~V}$ for $2500 \mathrm{~V} / \mathrm{h}$, and $8000 \mathrm{~V}$ for $3237 \mathrm{~V} / \mathrm{h}$, and finally $8000 \mathrm{~V}$ for $24000 \mathrm{~V} / \mathrm{h}$. The strips were equilibrated for $15 \mathrm{~min}$ in $5 \mathrm{~mL}$ of solution per strip containing $50 \mathrm{mM}$ Tris- $\mathrm{HCl}, \mathrm{pH}$
8.8, $6 \mathrm{M}$ urea, 30\% (v/v) glycerol, $2 \%(\mathrm{w} / \mathrm{v})$ SDS, with the addition of $0.1 \%(\mathrm{w} / \mathrm{v})$ DTT and $0.25 \%(\mathrm{w} / \mathrm{v})$ iodoacetamide, respectively, in the same solution composition. The equilibrated IPG strips were placed on the top of the $12.5 \%$ SDS gel, sealed with $0.5 \%(\mathrm{w} / \mathrm{v})$ agarose, and run for $15 \mathrm{~min}$ on $30 \mathrm{~mA}$, followed by $30 \mathrm{~mA}$ per gel until the end of the run. Silver staining was performed with "Silver staining kit-protein" (Amersham Biosciences), and gel images were analyzed using ImageMaster 2D Platinum (Amersham Biosciences).

In Situ Gel Digestion. Complete Coomassie destaining of excised gel bands/spots was performed by shrinking and rehydratating the gel pieces with acetonitrile and $50 \mathrm{mM}$ ammonium bicarbonate, respectively. After vacuum drying in Speedvac (Thermo, San Jose, CA), the excised bands were rehydratated and submitted first to chemical reduction in a solution of $10 \mathrm{mM}$ DTT in $50 \mathrm{mM}$ ammonium bicarbonate left for $30 \mathrm{~min}$ at $56^{\circ} \mathrm{C}$, and then to alkylation with a iodoacetamide solution in $50 \mathrm{mM}$ ammonium bicarbonate in the dark, for 30 $\mathrm{min}$, at room temperature. In situ digestion was performed on both bands and spots by rehydrating the gel plugs with a solution of $12 \mathrm{ng} / \mathrm{L}$ and $6 \mathrm{ng} / \mu \mathrm{L}$, respectively, of modified trypsin (Promega, Madison, WI) in $10 \mathrm{mM}$ ammonium bicarbonate solution and left to incubate for $90 \mathrm{~min}$ at $4{ }^{\circ} \mathrm{C}$. Supernatants were recovered, blocked by adding $10 \%$ TFA, and spotted on an AnchorChip (Bruker Daltonics, Bremen, Germany) target plate. One microliter of sample was deposited on the target plate and allowed to dry; $0.35 \mu \mathrm{L}$ of matrix $(5 \mathrm{~g} / \mathrm{L}$ $\alpha$-cyano-4-hydroxycinnamic acid in 50/50 acetonitrile/0.1\% TFA) was then added and, again, allowed to dry. To the remaining gel plugs, $30 \mu \mathrm{L}$ of $10 \mathrm{mM}$ ammonium bicarbonate was added, and the reaction proceeded overnight at $37^{\circ} \mathrm{C}$. Supernatants were eventually withdrawn and analyzed by MALDI MS and MS/MS.

MALDI Peptide Mass Fingerprinting. Mass spectrometry analysis was performed on a matrix-assisted laser desorption ionization tandem mass spectrometer having time-of-flight/ time-of-flight optics (Ultraflex MALDI-TOF/TOF, Bruker Daltonics) by using the data acquisition software FlexControl 2.4. Mass spectra were acquired in reflectron mode over the $\mathrm{m} / \mathrm{z}$ range $800-3500$. The instrumental parameters were chosen by setting the ion source 1 at $25 \mathrm{kV}$, the reflector at $26.30 \mathrm{kV}$, and the delay time at $20 \mathrm{~ns}$. The instrument was externally calibrated prior to analysis by using the Bruker peptide calibrant kit (1000-3000 Da), and the sample spectra were internally recalibrated with trypsin autolysis signals. Mass spectra were elaborated by using FlexAnalysis 2.4. The peptide masses present in each mass spectrum, through the integrated software Biotools2.2., are used to search the NCBI nonredundant database by using MASCOT software available online (http://www.matrixscience.com/cgi/nph-mascot.exe?1), which compares the experimentally determined tryptic peptide masses with theoretical ones calculated for proteins contained in the protein database. When NCBInr is used as protein databank to search against, Mascot significance threshold is 64. The taxonomy was set on Archea; carbamidomethylation and methionine oxidation were selected as complete and partial modifications, respectively; two missed cleavages were allowed for trypsin chosen as cleaving agent. Searches were performed setting a mass tolerance ranging from 20 to $40 \mathrm{ppm}$. Quick confirmation of our results was made by searching also against the Swiss-Prot (http://expasy.org/sprot) database by using the softwares Profound (http://65.219.84.5/service/prowl/profound/ profound_E_adv.html) and MS-FIT (http://prospector.ucsf.edu/ 
ucsfhtml4.0/msfit.htm) which use different searching algorithms to identify proteins. The accession numbers were retrieved from the NCBI (http://www.ncbi.nlm.nih.gov).

MALDI MS/MS Peptide Sequencing. The best S/N peptides signals present in each MS spectrum and those identifying the protein were submitted to MS/MS analysis on the Ultraflex MALDI-TOF/TOF by using LIFT technology (Bruker Daltonics).

Miscellaneous Biochemical and Spectroscopic Methods. Protein purity was monitored by $12.5 \%$ SDS-PAGE. Gels were stained with Coomassie brilliant blue $\mathrm{G}$ or silver (Silver staining kit-protein, Amersham Biosciences), and images were obtained on ImageScanner (Amersham Biosciences). Protein content was determined by the Bradford ${ }^{24}$ quantification method. UV and visible spectra were recorded on UV-1700 Shimadzu spectrophotometer. Folded structure of ferredoxin purified from the thermally treated proteome was tested with fluorescence spectroscopy measurements (Cary Varian Eclipse spectrofluorimeter), monitoring tryptophan fluorescence emission between $300-450 \mathrm{~nm}$, with excitation at $280 \mathrm{~nm}$. Peroxidase activity of the Bacterioferritin comigratory protein (BCP) was tested by its ability to remove added $\mathrm{H}_{2} \mathrm{O}_{2}$ from a reaction mixture containing $50 \mathrm{mM}$ HEPES, $\mathrm{pH} 7$, and $10 \mathrm{mM}$ DTT as electron donor, at $25^{\circ} \mathrm{C}$ using an amperometric $\mathrm{H}_{2} \mathrm{O}_{2}$ detection (WPI Apollo 4000 system). Assay of SOD activity was done at $25{ }^{\circ} \mathrm{C}$ by the xanthine/xanthine oxidase method ${ }^{25}$ in $50 \mathrm{mM}$ phosphate buffer, pH 7.8, with 0.1 mM EDTA; one activity unit was defined as the amount of enzyme that caused $50 \%$ inhibition of the cytochrome $c$ reduction by superoxide $\left(\mathrm{O}_{2}{ }^{-}\right)$.

\section{Results and Discussion}

High Temperature and Chemical Denaturants Induce Proteome Perturbation. The cytosolic proteomes obtained from Sulfurisphaera cells grown at $72{ }^{\circ} \mathrm{C}$ (SulfCP72) and $92{ }^{\circ} \mathrm{C}$ (SulfCP92) were perturbed by two different protocols. The thermal perturbation protocol consisted in incubation at 90 ${ }^{\circ} \mathrm{C}$ for up to $96 \mathrm{~h}$, sampling every $24 \mathrm{~h}$. After $96 \mathrm{~h}$ incubation, the protein yield was $5 \%$. To detail the enrichment of the thermostable proteome, a combination of small-scale ionic exchange and SDS-PAGE was used. Aliquots of the SulfCP72 proteome, which had been sampled during different periods of the thermal perturbation protocol, were applied into a HiTrap Q-sepharose FF column for chromatographic separation. From the obtained protein chromatograms, it became clear that the extract is being selectively enriched in thermostable proteins, which eluted at identical ionic strengths despite the longer incubation at $96{ }^{\circ} \mathrm{C}$ (Figure 1). This provided a good indication that the tertiary fold of the proteins in solution was kept; in fact, protein unfolding results in the exposure of a higher number of side chains thus changing the charged surface with respect to the native state, resulting in a modification of the elution profile which is not the case. The global impact of the thermal perturbation on the proteome was also investigated by SDS-PAGE analysis (Figure 2). An increasingly lower number of bands were observed as the incubation time increases, evidencing protein selection. Identical results were obtained for cells grown at $92{ }^{\circ} \mathrm{C}$. The second perturbation protocol involved the combined use of high temperature $\left(90^{\circ} \mathrm{C}\right)$ and a moderate concentration $(1 \mathrm{M})$ of the chemical denaturant guanidinium hydrochloride ( $\mathrm{GuHCl}$ ). SDS-PAGE analysis shows that the presence of denaturant is sufficient to significantly reduce the time necessary to produce a subset of the proteome (24 and $48 \mathrm{~h}$ ) (Figure 2). Interestingly, a comparable profile was obtained from both perturbation protocols on SDS-PAGE,

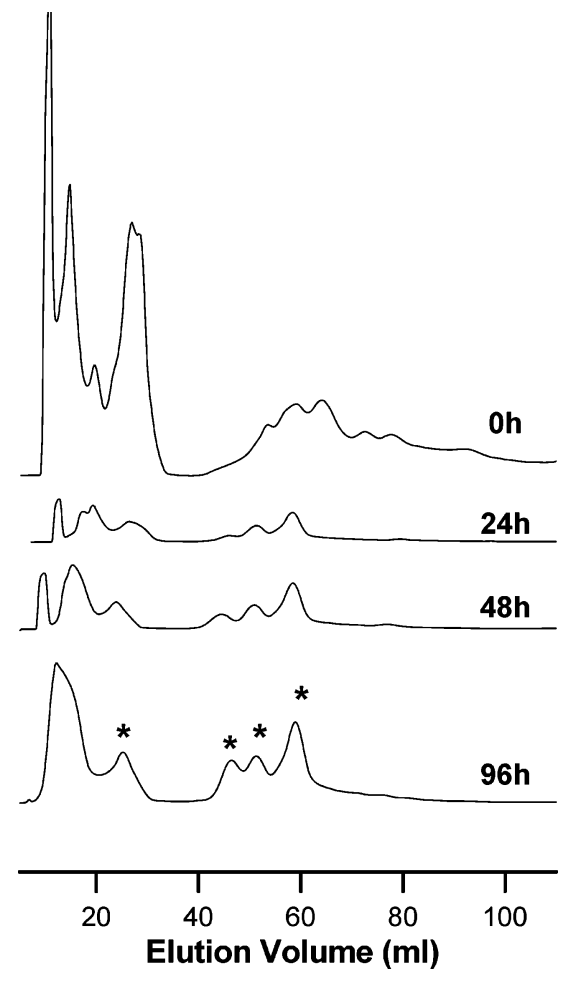

Figure 1. Protein chromatograms of purification of SulfCP72 thermally treated proteome. The extract is being selectively enriched in thermostable proteins (marked with an asterisk), which elute at identical ionic strengths despite the longer incubation at $90^{\circ} \mathrm{C}$. In agreement, a decreasing number of bands were observed in denaturing electrophoresis (see Figure 2).

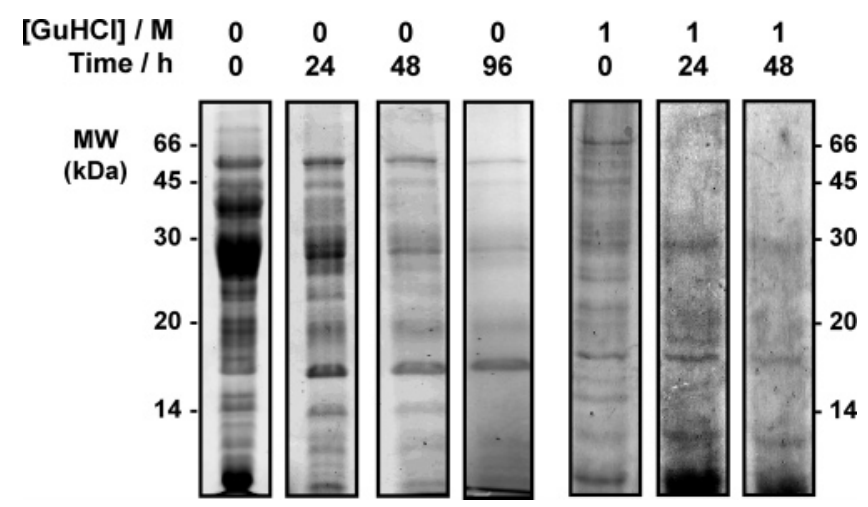

Figure 2. SDS-PAGE analysis of the Sulfurisphaera cytosolic proteome. The SulfCP72 cytosolic extract was incubated at 90 ${ }^{\circ} \mathrm{C}$ up to $96 \mathrm{~h}$ either in the absence or in the presence of $\mathrm{GuHCl}$. Each lane was loaded with $\approx 1 \mu \mathrm{g}$ of protein. Gels were Silverstained.

suggesting a common selection toward proteins with enhanced stability properties.

To further investigate and identify some of these proteins, $13 \mathrm{~cm}$ gels were prepared from SulfCP72 and SulfCP92 which had been incubated for $24 \mathrm{~h}$ at $90^{\circ} \mathrm{C}$ in presence of $1 \mathrm{M} \mathrm{GuHCl}$ as well as in its absence (Figure 3). From these gels, relevant bands were excised and subjected to MALDI-TOF/TOF analysis, leading to the identification of five proteins: a DNA binding protein $7 \mathrm{e}$ (DNA-BP, $\approx 14 \mathrm{kDa}$ ), the bacterioferritin comigratory protein $(\mathrm{BCP}, \approx 21 \mathrm{kDa}$ ), a superoxide dismutase (SOD, $\approx 28$ $\mathrm{kDa}$ ), the large subunit of an hypothetical CO dehydrogenase (CO DH, $\approx 80 \mathrm{kDa}$ ), and a hypothetical Acyl-CoA dehydrogenase 


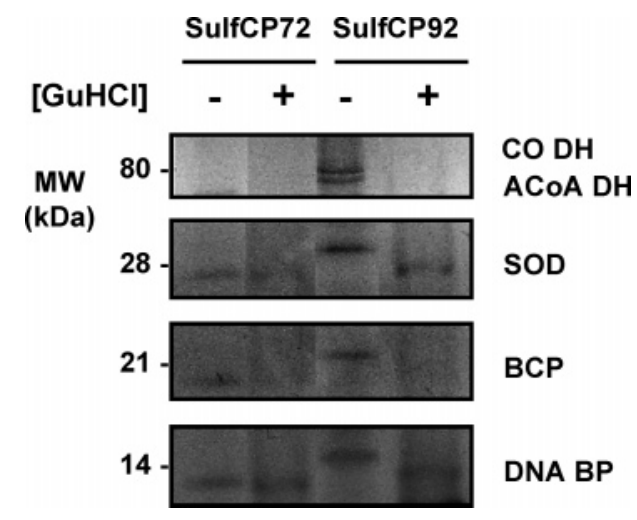

Figure 3. Detail of a $13 \mathrm{~cm}$ resolving $12.5 \%$ SDS-PAGE Silverstained gel highlighting proteins whose excision led to their identification by mass spectrometry. The SulfCP72 and SulfCP92 cytosolic proteomes were incubated during $24 \mathrm{~h}$ in the presence $(+)$ or absence (-) of $1 \mathrm{M} \mathrm{GuHCl}$. The chemical denaturant was removed by extensive dialysis prior to electrophoresis. DNA BP, DNA binding protein Alba-2; BCP, bacterioferritin comigratory protein; SOD, superoxide dismutase; $\mathrm{CO} D \mathrm{DH}$, hypothetical $\mathrm{CO}$ dehydrogenase large subunit; and ACoA DH, hypothetical acylCoA dehydrogenase. See also Table 1 for details.

(ACoA DH, $\approx 78 \mathrm{kDa}$ ) (Figure 3 and Table 1). These proteins have enhanced stabilities with respect to the total proteome, but they are not all equally stable; for example, whereas the DNA binding protein and the SOD are found in thermally and chemically perturbed extracts, the BCP and the dehydrogenases are more susceptible to simultaneous chemical degradation. In fact, the slight differences observed in the electrophoretic mobility of these proteins may be suggestive of moderately perturbed conformational states.

Proteome Analysis by 2DE and MS: Identification of Hyperstable Proteins. The cytosolic fractions perturbed during $96 \mathrm{~h}$ at $90{ }^{\circ} \mathrm{C}$ were further resolved by two-dimensional electrophoresis. The SulfCP92 proteome was analyzed before and after the thermal perturbation (Figure 4): it became clear that the number of proteins decreases substantially and that even after such extensive incubation there is still a large number of proteins detected. Proteins present in the native (Figure 4A) and thermally perturbed (Figure 4B) SulfCP92 proteome were selected for further investigation by MALDI peptide mass fingerprinting. Excised gel spots were digested and submitted to MALDI peptide mass fingerprinting analysis. To confirm protein identifications, the lists of the identifying peptide masses deriving from each spot were carefully inspected searching for the best $\mathrm{S} / \mathrm{N}$ peptides signal to sequence. The structural information deriving from both the peptide mass fingerprinting and the MS/MS-derived peptide sequences greatly enhanced the protein identification confidence. The subset of proteins identified from analysis of the 2DE gel (Table 1) can be grouped into three distinct functional categories: proteins involved in cellular processes and detoxification; DNA binding, translation, and protein modification; and energy metabolism. Two of the identified proteins, superoxide dismutase and Bacterioferritin comigratory protein (BCP, a peroxiredoxin) had already been identified from the $1 \mathrm{D}$ gel analysis. Four identified proteins (DNA binding protein Alba2 , hypothetical DNA-binding protein 7e, hypothetical elongation factor 1-alpha, Thermosome $\beta$ subunit) are involved in nucleic acid processing and protein modification processes. In particular the DNA binding protein Alba-2 was previously identified by analyzing 1D gel of perturbed proteome. Finally, eight proteins involved in energy metabolism processes were identified, among which are several hypothetical dehydrogenases and the iron-sulfur protein ferredoxin (Table 1). MALDI MS and MS/MS spectra of superoxide dismutase, DNA binding protein Alba-2, and ferredoxin, each belonging to one of the three different biological classes, have been selected as an example and reported in Figure 5.

The type of cellular processes in which the identified proteins are involved is very interesting and noteworthy from the point of view of the Sulfurisphaera's optimal growth conditions at high temperatures. The identified proteins participate in cellular processes (e.g., defense against reactive oxygen species, nucleic acid protection, and energy production) in which some key proteins have enhanced thermal stabilities, which may relate to their importance on the metabolism of a thermophile. For example, at temperatures above $70^{\circ} \mathrm{C}$, DNA is particularly susceptible to chemical modifications, mainly depurination followed by cleavage of the nearby phosphodiesteric bond, thus, making DNA binding proteins particularly important as these wind and compact DNA, protecting it. ${ }^{1}$ In agreement, several DNA-binding proteins were identified in this study

Table 1. Selected Proteins Identified from the Cytosolic Sulfurisphaera Proteome after Perturbation

\begin{tabular}{|c|c|c|c|c|}
\hline spot & protein annotation & $\begin{array}{c}\text { MW } \\
(\mathrm{kDa})\end{array}$ & $\mathrm{p} I$ & $\begin{array}{c}\text { homologue accession } \\
\text { number }\end{array}$ \\
\hline \multicolumn{5}{|c|}{ Celullar Processes/Detoxification } \\
\hline 1 & Superoxide dismutase ${ }^{a}$ & 24.3 & 3.2 & 15922615 \\
\hline 2 & Bacterioferritin comigratory protein (Peroxiredoxin)* & 17.7 & 7.5 & 15922097 \\
\hline \multicolumn{5}{|c|}{ DNA Binding/Translation/Protein Modification } \\
\hline 3 & DNA binding protein Alba- $2^{a}$ & 10.5 & n.d. & 68567728 \\
\hline 4 & hypothetical DNA-binding protein $7 \mathrm{e}$ & 7.3 & 10 & 15621644 \\
\hline 5 & hypothetical elongation factor 1-alpha & 48.3 & 10 & 15920458 \\
\hline 6 & Thermosome $\beta$ subunit & 60.7 & 5.4 & 15920519 \\
\hline \multicolumn{5}{|c|}{ Energy Metabolism } \\
\hline 7 & hypothetical CO dehydrogenase large subunit ${ }^{a}$ & 81.8 & n.d. & 15922093 \\
\hline 8 & hypothetical CO dehydrogenase middle subunit & 31.2 & 10 & 15922095 \\
\hline 9 & hypothetical acetil-CoA synthetase & 74.5 & n.d. & BAB65737 \\
\hline 10 & hypothetical glutamate dehydrogenase (hyp) & 45.7 & 6.1 & 15922573 \\
\hline 11 & hypothetical sulphide dehydrogenase & 43.0 & 6.8 & 15920835 \\
\hline 12 & hypothetical L-lactate dehydrogenase & 34.7 & 6.3 & 15622912 \\
\hline 13 & Ferredoxin $[3 \mathrm{Fe} 4 \mathrm{~S}][4 \mathrm{Fe} 4 \mathrm{~S}]$ & 11.3 & 5.5 & 2554684 \\
\hline 14 & hypothetical metal-dependent hydrolase & 25.5 & 5.8 & 22096255 \\
\hline
\end{tabular}

${ }^{a}$ Denotes proteins identified also from 1D SDS-PAGE gel bands. N.d., not determined. 

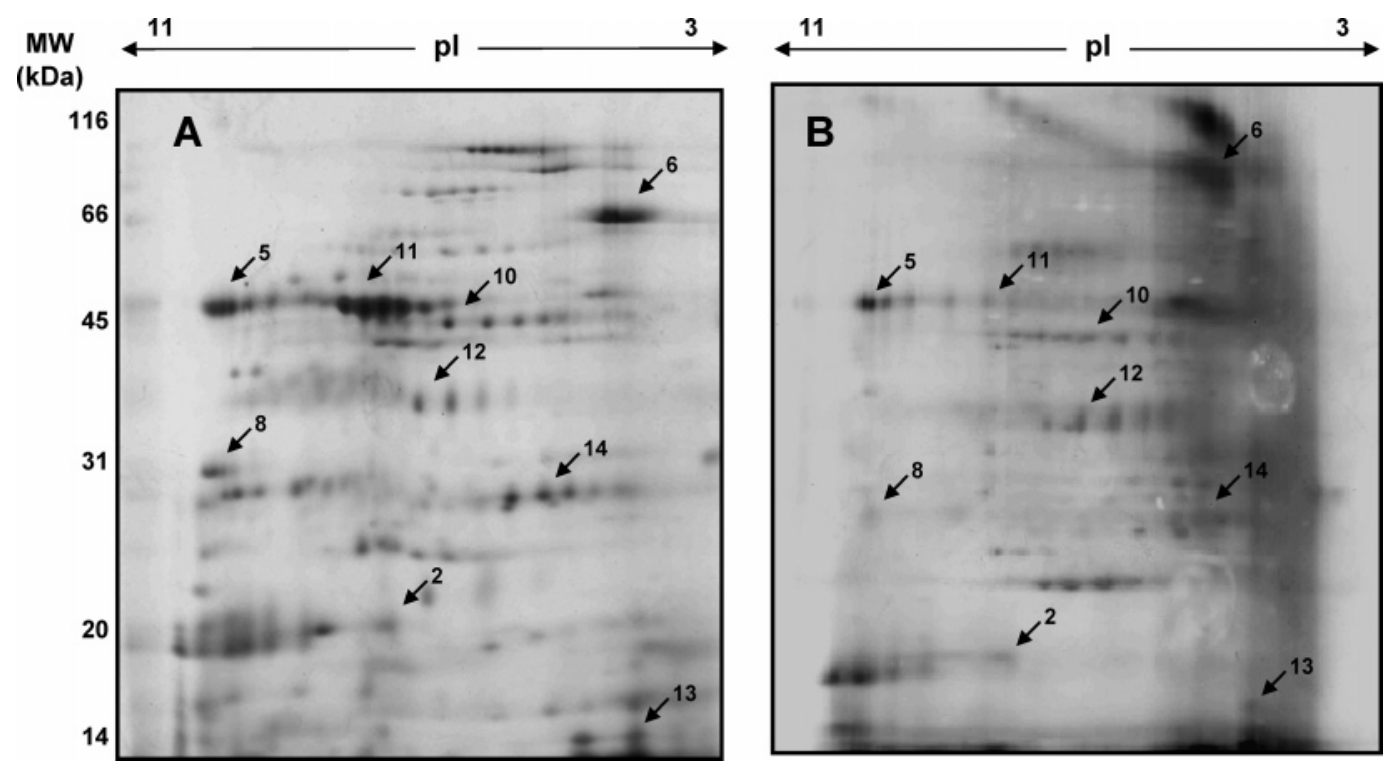

Figure 4. 2DE Silver-stained gel (12.5\% SDS-PAGE) using a $13 \mathrm{~cm}, 3-11 \mathrm{NL}$ IPG strip, resulting from the application of $500 \mu \mathrm{g}$ of total protein. (A) Native SulfCP92 without any heat treatment. (B) Subset of the perturbed proteome obtained after $96 \mathrm{~h}$ incubation at $90{ }^{\circ} \mathrm{C}$. Numbered arrows indicate spots which were selected for identification (see Table 1 for details).

(Table 1). Concerning the energy metabolism proteins, the hypothetical dehydrogenases identified suggest that some electron-transfer pathways involved in energy production processes involve particularly stable proteins. A common feature among these proteins is that they comprise a NAD(P)binding Rossman fold; however, since this is one of the most populated folds in proteins, typical among dehydrogenases, a direct correlation with enhanced protein stability cannot be postulated. Finding proteins involved in cellular detoxification processes to be hyperstable may be rationalized with the fact that high temperatures and aerobic growth conditions are prone to an increased cellular oxidative stress. In these circumstances, the amount of reactive oxygen species (ROS) formed during electron-transfer processes is likely to be increased as a result of electron leakage from redox proteins and reduced cofactors. This calls for a particularly stable set of ROS defense proteins such as peroxiredoxin and superoxide dismutase (Table 1). Altogether, these results suggest that some metabolic processes in thermophiles may require a 'thermostable character' in order to cope with the specificities of life at high temperatures.

Proteins from the Pool of Selected Hyperstable Proteins Are Biologically Active. Thermophilic proteins can be intrinsically very stable and exhibit a very high kinetic stability toward thermal degradation. We have validated our proteome perturbation method by verifying the extent to which the subset of proteins obtained after the perturbation corresponds to biologically active molecules. Three distinct proteins were selected from the perturbed subset: the iron-sulfur protein ferredoxin (Fd), the peroxiredoxin Bacterioferritin comigratory protein (Prx-BCP), and superoxide dismutase (SOD). Whereas Fd is an electron carrier present in most thermoacidophilic Archaea, Prx-BCP and SOD are enzymes that are, respectively, involved in the detoxification of peroxides and superoxide. For this characterization, we have set up a small-scale two-step chromatographic procedure for partly resolving the thermally perturbed SulfCP92 proteome. Starting from the $96 \mathrm{~h}$ incubated SulfCP92 proteome, and using a combination of anionic exchange (Q-sepharose HiPrep) and gel filtration (S-75), a protein fraction corresponding to a molecular weight of $\approx 12$ $\mathrm{kDa}$, as determined from SDS-PAGE, was obtained. Sequencing of its N-terminus (1-GIDPNYRTNRQVVGEHSK-G) clearly showed that this protein corresponds to ferredoxin.

A preliminary biophysical characterization was carried out on this purified band, and its assignment as a Fd was corroborated by obtaining the typical UV-visible spectrum, with the characteristic band at $410 \mathrm{~nm}$ corresponding to native $\mathrm{Fd}$ with intact $\mathrm{Fe}-\mathrm{S}$ clusters (not shown). The Sulfurisphaera ferredoxin has orthologues in other thermophilic Sulfolobales, ${ }^{11,16}$ and these proteins are characterized by a very high thermal stability; they have very high midpoint melting transitions $\left(T_{\mathrm{m}}=110^{\circ} \mathrm{C}\right.$ at $\mathrm{pH} 7$ for the Acidianus ambivalens $\left.\mathrm{Fd}\right)$ as well as a very high kinetic stability. ${ }^{11}$ The protein core harboring the two iron-sulfur centers is likely to play an important role in protein thermostability, as well as a $\mathrm{Zn}$-containing $\mathrm{N}$ terminal extension. ${ }^{11,26}$

The $\mathrm{SOD}^{27}$ and Prx-BCP ${ }^{28}$ activities were measured in the native and perturbed SulfCP72 proteome. Not only were both activities present, but also a specific activity increase of the enzymes was observed (Figure 6). This observation is compatible with a significant enrichment of these two enzymes in the thermally treated extract, as a result of their enhanced thermostability. Whereas little is yet known concerning the molecular origins of Prx-BCP stability, there are several studies on thermophilic SODs. ${ }^{27}$ The available data on Archaeal FeSODs corroborates our finding that these proteins are among the most thermostable in the cell. For example, the Sulfolobus acidocaldarius SOD, which is a functional tetramer, has a very high stability undergoing structural thermal melting at $125^{\circ} \mathrm{C}$, a temperature which is $40{ }^{\circ} \mathrm{C}$ above the organism optimal growth temperature. ${ }^{27}$ Structural analysis suggests that the increase protein stability may result from its quaternary structure, a tight packing of buried hydrophobic residues, and an increased number of ion pairs. ${ }^{27}$

\section{Conclusions}

Here we have outlined an experimental strategy which allows mining proteomes for proteins having enhanced stability 

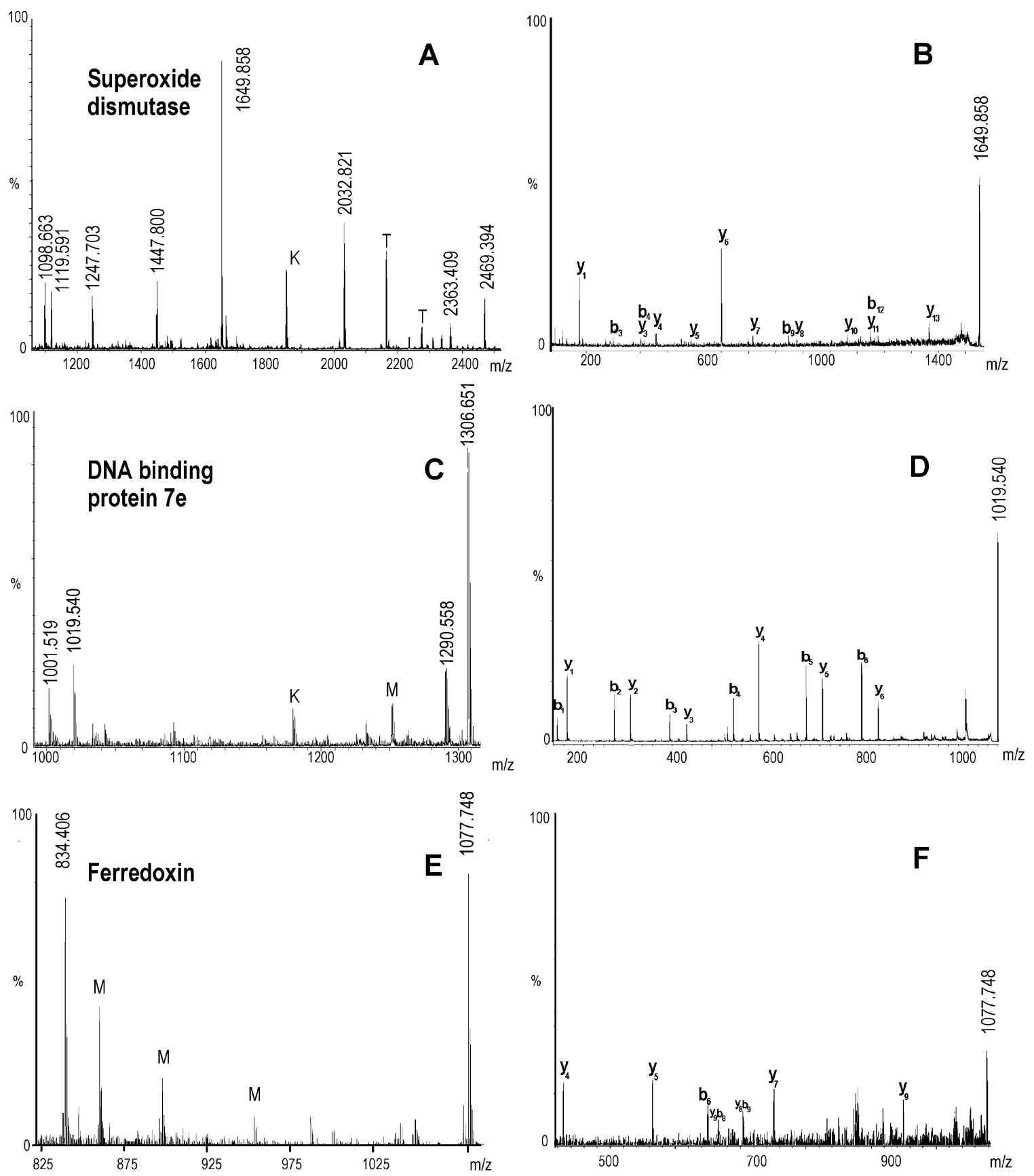

Figure 5. MALDI MS and MALDI MS/MS spectra of 3 out of 14 identified proteins from Sulfurisphaera. (A, C, and E) Panels show the MALDI MS spectra of superoxide dismutase, hypothetical DNA-binding protein, and ferredoxin, respectively. $K$, M, and T stand for keratin, matrix, and trypsin mass signals, respectively. (B, D, and F) Panels show the corresponding MALDI MS/MS spectra of the above proteins where a peptide mass signal was chosen for each protein (1649.858, 1019.540, and 1077.748, respectively) and submitted to tandem MS in order to confirm protein identifications. See table in Supporting Information for assignments.

properties. This approach is particularly valuable for the identification of proteins which can be used in subsequent studies aimed at the understanding of protein stability, function, or structural features. Following our interest in the study of conformational properties of thermophilic proteins, we have selected Sulfurisphaera sp. as a model organism to implement this methodology; the identification of hyperstable proteins in a thermophilic background required drastic perturbation protocols (e.g., 4 days at $90{ }^{\circ} \mathrm{C}$ ), which nevertheless resulted in the identification of a subset of proteins which remained folded after the perturbation and provided an insightful perspective into the type of essential cellular processes requiring particu- larly resistant proteins. In fact, many of the identified proteins are involved in stress response mechanisms that aim at protecting nucleic acids and proteins from aggression elements such as thermal stress and reactive oxygen species. In this respect, this approach highlighted not only proteins interesting for subsequent stability studies, but also key metabolic processes which may have themselves a 'thermophilic character'. Recently, efficient expression systems have been developed ${ }^{29}$ using the closely related hyperthermophile Sulfolobus solfataricus as an efficient expression system of tagged proteins, thus, greatly facilitating the production of proteins of interest such as those identified in this work for subsequent studies. 


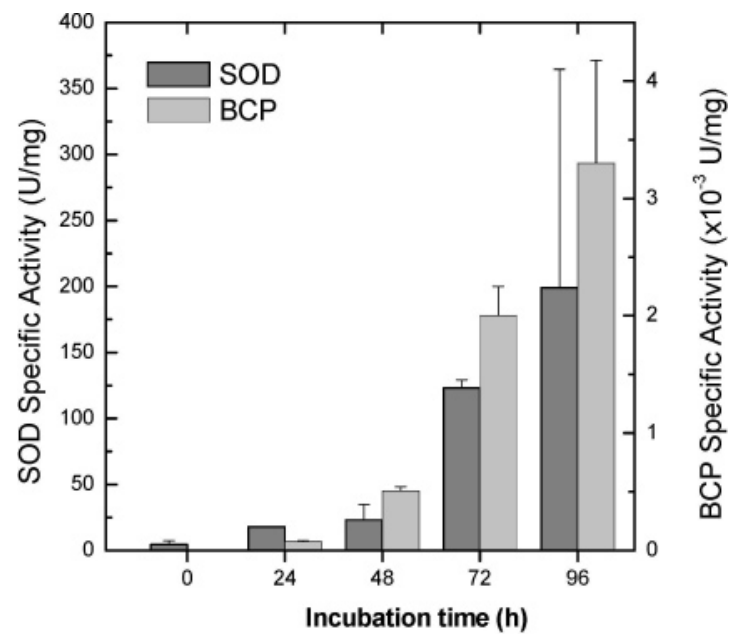

Figure 6. Variation of the BCP and SOD specific activity as a function of incubation time of the SulfCP92 proteome. Error bars are from the standard deviation of activity assays $(n=2)$.

Acknowledgment. This work was supported by research grants POCTI/QUI/45758 and POCTI/BIO/58465 (to C.M.G.) from the Fundação para a Ciência e a Tecnologia (FCT/MCES, Portugal). V.P. is a recipient of a Ph.D fellowship (SFRH/BD/ 18746/2004) from Fundação para a Ciência e a Tecnologia (FCT/MCES, Portugal). M. Regalla (Amino Acid Sequencing Service, ITQB) is thanked for N-terminal analysis. Rita Francisco (ITQB) is gratefully acknowledged for technical advice in $2 \mathrm{DE}$ electrophoresis. CISM acknowledges Ente Cassa di Risparmio di Firenze for financial support for purchasing the Ultraflex MALDI-TOF/TOF.

Supporting Information Available: MALDI MS and MS/MS signal assignments. This material is available free of charge via the Internet at http://pubs.acs.org.

\section{References}

(1) Madigan, M. T.; Oren, A. Thermophilic and halophilic extremophiles. Curr. Opin. Microbiol. 1999, 2 (3), 265-269.

(2) Vieille, C.; Zeikus, G. J. Hyperthermophilic enzymes: sources, uses, and molecular mechanisms for thermostability. Microbiol. Mol. Biol. Rev. 2001, 65 (1), 1-43.

(3) Martins, L. O.; Huber, R.; Huber, H.; Stetter, K. O.; Da Costa, M. S.; Santos, H. Organic solutes in hyperthermophilic archaea. Appl. Environ. Microbiol. 1997, 63 (3), 896-902.

(4) Petsko, G.; Ringe, D. Protein Structure and Function; New Science Press: London, 2004.

(5) Cowan, D. A. Biotechnology of the Archaea. Trends Biotechnol. 1992, $10(9), 315-323$.

(6) Li, W. F.; Zhou, X. X.; Lu, P. Structural features of thermozymes. Biotechnol. Adv. 2005, 23 (4), 271-281.

(7) Fitter, J. Structural and dynamical features contributing to thermostability in alpha-amylases. Cell. Mol. Life Sci. 2005, 62 (17), 1925-1937.

(8) Gomes, C. M.; Kletzin, A.; Teixeira, M. An archaeal b-type cytochrome containing a nonfunctional carbonic anhydrase-like domain. J. Biol. Inorg. Chem. 2002, 7 (4-5), 483-489.

(9) Perl, D.; Schmid, F. X. Electrostatic stabilization of a thermophilic cold shock protein. J. Mol. Biol. 2001, 313 (2), 343-357.

(10) Urich, T.; Gomes, C. M.; Kletzin, A.; Frazao, C. X-ray Structure of a self-compartmentalizing sulfur cycle metalloenzyme. Science 2006, 311 (5763), 996-1000.

(11) Gomes, C.; Faria, A.; Carita, J.; Mendes, J.; Regalla, M.; Chicau, P.; Huber, H.; Stetter, K.; M, T. Di-cluster, seven-iron ferredoxins from hyperthermophilic Sulfolobales. JBIC, J. Biol. Inog. Chem. 1998, 3 (1), 499-507.
(12) Gomes, C. M.; Frazao, C.; Xavier, A. V.; Legall, J.; Teixeira, M. Functional control of the binuclear metal site in the metallobeta-lactamase-like fold by subtle amino acid replacements. Protein Sci. 2002, 11 (3), 707-712.

(13) Gomes, C. M.; Vicente, J. B.; Wasserfallen, A.; Teixeira, M. Spectroscopic studies and characterization of a novel electrontransfer chain from Escherichia coli involving a flavorubredoxin and its flavoprotein reductase partner. Biochemistry 2000, 39 (51), 16230-16237.

(14) Henriques, B. J.; Saraiva, L. M.; Gomes, C. M. Probing the mechanism of rubredoxin thermal unfolding in the absence of salt bridges by temperature jump experiments. Biochem. Biophys. Res. Commun. 2005, 333 (3), 839-844.

(15) Henriques, B. J.; Saraiva, L. M.; Gomes, C. M. Combined spectroscopic and calorimetric characterisation of rubredoxin reversible thermal transition. J. Biol. Inorg. Chem. 2006, 11 (1), 73-81.

(16) Leal, S. S.; Gomes, C. M. Linear three-iron centres are unlikely cluster degradation intermediates during unfolding of iron-sulfur proteins. Biol. Chem. 2005, 386 (12), 1295-1300.

(17) Leal, S. S.; Teixeira, M.; Gomes, C. M. Studies on the degradation pathway of iron-sulfur centers during unfolding of a hyperstable ferredoxin: cluster dissociation, iron release and protein stability. J. Biol. Inorg. Chem. 2004, 9 (8), 987-996.

(18) Wittung-Stafshede, P.; Gomes, C. M.; Teixeira, M. Stability and folding of the ferredoxin from the hyperthermophilic archaeon Acidianus ambivalens. J. Inorg. Biochem. 2000, 78 (1), 35-41.

(19) Kurosawa, N.; Itoh, Y. H.; Iwai, T.; Sugai, A.; Uda, I.; Kimura, N.; Horiuchi, T.; Itoh, T. Sulfurisphaera ohwakuensis gen. nov., sp. nov., a novel extremely thermophilic acidophile of the order Sulfolobales. Int. J. Syst. Bacteriol. 1998, 48 (Pt 2), 451-456.

(20) Kawarabayasi, Y.; Hino, Y.; Horikawa, H.; Jin-no, K.; Takahashi, M.; Sekine, M.; Baba, S.; Ankai, A.; Kosugi, H.; Hosoyama, A.; Fukui, S.; Nagai, Y.; Nishijima, K.; Otsuka, R.; Nakazawa, H.; Takamiya, M.; Kato, Y.; Yoshizawa, T.; Tanaka, T.; Kudoh, Y.; Yamazaki, J.; Kushida, N.; Oguchi, A.; Aoki, K.; Masuda, S.; Yanagii, M.; Nishimura, M.; Yamagishi, A.; Oshima, T.; Kikuchi, H. Complete genome sequence of an aerobic thermoacidophilic crenarchaeon, Sulfolobus tokodaii strain7. DNA Res. 2001, 8 (4), 123-140.

(21) Chong, P. K.; Wright, P. C. Identification and characterization of the Sulfolobus solfataricus P2 proteome. J. Proteome Res. 2005, 4 (5), 1789-1798.

(22) Urich, T. Ein neuer Stoffwechselweg bei Archaeen: Untersuchungen zur anaeroben Schwefeldisproportionierung bei Acidianus ambivalens und Sulfurisphaera sp. Diploma Thesis, Darmstadt University of Technology, Darmstadt, Germany, 2001.

(23) Teixeira, M.; Batista, R.; Campos, A. P.; Gomes, C.; Mendes, J.; Pacheco, I.; Anemuller, S.; Hagen, W. R. A seven-iron ferredoxin from the thermoacidophilic archaeon Desulfurolobus ambivalens. Eur. J. Biochem. 1995, 227 (1-2), 322-327.

(24) Bradford, M. M. A rapid and sensitive method for the quantitation of microgram quantities of protein utilizing the principle of protein-dye binding. Anal. Biochem. 1976, 72, 248-254.

(25) McCord, J. M.; Fridovich, I. Superoxide dismutase. An enzymic function for erythrocuprein (hemocuprein). J. Biol. Chem. 1969, 244 (22), 6049-6055.

(26) Rocha, R.; Leal, S.; Teixeira, V.; Regalla, M.; Huber, H.; Baptista, A.; Soares, C. M.; Gomes, C. M. Natural domain design: enhanced thermal stability of a zinc lacking ferredoxin isoform shows that a hydrophobic core efficiently replaces the structural metal site. Biochemistry 2006, 45, 10376-10384.

(27) Schafer, G.; Kardinahl, S. Iron superoxide dismutases: structure and function of an archaic enzyme. Biochem. Soc. Trans. 2003, 31 (Pt 6), 1330-1334.

(28) Limauro, D.; Pedone, E.; Pirone, L.; Bartolucci, S. Identification and characterization of 1-Cys peroxiredoxin from Sulfolobus solfataricus and its involvement in the response to oxidative stress. FEBS J. 2006, 273 (4), 721-731.

(29) Albers, S. V.; Jonuscheit, M.; Dinkelaker, S.; Urich, T.; Kletzin, A.; Tampe, R.; Driessen, A. J.; Schleper, C. Production of recombinant and tagged proteins in the hyperthermophilic archaeon Sulfolobus solfataricus. Appl. Environ. Microbiol. 2006, 72 (1), 102-111.

\section{PR0602491}

